\title{
A Review of Skylight Glazing Materials in Architectural Designs for a Better Indoor Environment
}

\author{
Karam M. Al-Obaidi ${ }^{1}$, Mazran Ismail ${ }^{1} \&$ Abdul Malek Abdul Rahman ${ }^{1}$ \\ ${ }^{1}$ School of Housing, Building and Planning, Universiti Sains Malaysia, 11800, Penang, Malaysia \\ Correspondence: Karam M. Al-Obaidi, School of Housing, Building and Planning, Universiti Sains Malaysia, \\ 11800, Penang, Malaysia. Tel: 60-174-039-378. E-mail: karam_arc@yahoo.com
}

Received: November 11, 2013

Accepted: December 10, 2013 Online Published: December 30, 2013

doi:10.5539/mas.v8n1p68

URL: http://dx.doi.org/10.5539/mas.v8n1p68

\begin{abstract}
Glazing materials have a significant impact on the energy efficiency of the building interior. Poorly designed skylights, windows and glazed surfaces can create an uncomfortable environment. The effect of heat gain through an un-shaded glass can be 100 times higher compared to the same area of an insulated wall. Currently, various alternative glazings with different performances are being used daily. There are many choices and alternatives to consider, and careful selection is significant to meet the design requirements. The optical features of glazing materials influence daylighting quality, the thermal characteristics and the potential of energy savings. The increasing interest of skylights as an effective strategy among building professionals and building owners implies that they are keen to know about the performance and energy efficiency of various glazing materials used on skylights. The aim of this study is to review the glazing performance and glazing types that are applied in the skylight roofing system. The review targets at two important factors in glazing performance, namely, solar light and solar heat. The review emphasises this general relationship during the design stage to ensure greater visibility in the product selection, also to ensure various other advantages improved comfort in perimeter zones, reduced mechanical loads and improved energy performance.
\end{abstract}

Keywords: skylight glazing materials, glazing properties, daylighting, solar heat

\section{Introduction}

Energy consumption has become the current topic of interest particularly that in building designs. The indications show that buildings consume about $57 \%$ of total primary energy requirement of Singapore, $47 \%$ of Switzerland, $42 \%$ of Brazil, $40 \%$ of the USA, $39 \%$ of Great Britain, $28 \%$ of China, $25 \%$ of Japan and $23 \%$ of Spain (Dong et al., 2005; Levermore, 2008; Masoso \& Grobler, 2010). Much of the energy in buildings is consumed by two significant elements as air conditioning systems and artificial lighting fixtures. In actual fact, the relation of these elements in most cases is connected, as most of lighting energy from the electric light systems are converted to thermal energy; consequently cooling systems are required to add more loads in summer time. Thus, designing buildings to be more environmentally friendly can lead to energy savings (Hassid, 2011).

Lighting building interior with natural light could be one of the contributors to help reduce energy consumption that provides a healthy indoor environment. Based on Edward (2005) there is an indication that the incident of sunlight rays on 1000 square centimetres of horizontal glass in sunny days can deliver efficiency almost twice that of the fluorescent lamp. Natural light, as clean lighting energy when it passes glazing materials, improves tenant's well-being and productivity, as well as decreases the energy used for artificial lighting. Nevertheless, it also brings with it thermal energy that adds a heavy load to the cooling system.

An appropriate design of skylight can minimize the cooling loads and can utilize the natural light as the most efficient source of renewable energy. There are several factors which control the design such as the size, the orientation, the placement, the amount of shading, as well as the glazing types. In reality, glazing types consider that the most essential factor must be addressed seriously in the skylight design (Carmody, 2007; Adelaide City Council, 2013).

Generally, the glazing material transfers various levels of environmental loads based on its properties. Understanding these properties will help the designer to control the excessive impact of natural light and guide 
the designer to select the most appropriate options. There are different studies carried out by Laouadi et al. (2002, 2003), Gueymard and DuPont (2009), Freire (2011) and Kim and Todorovic (2013). However, all these studies are based on empirical researches which do not cover any studies relating to the physical glazing condition in the skylight design, as well as those which have not identified the performance of different glazing types for building professionals. Therefore, the aim of this study is to review the most important physical factors of glazing materials that influence the process of the architectural design especially those that relate to the performance of solar light and solar heat in various types of the existing materials.

\section{Glazing Performance}

\subsection{Glazing Overview}

Glass is one of the commonest man-made materials that have been in use for a long time. It was first discovered around 1500 B.C in Mesopotamia and Egypt, then the Romans further developed its production in the first century A.D. In 1665, Royal Glassworks for the first time manufactured mirrors for the 'Palace of Versailles' in France. In 1773, England became the world's leading manufacturer for quality glass for windows. In the 1950s glass manufacturing was transformed for good when Alastair Pilkington invented the float glass. It cut down the cost of glass drastically and formed innovative applications such as the exterior of high rise buildings (Garg, 2007).

Glass is a physical substance that has special features to prove the functional demands, which create the interior and exterior of a skylight. Therefore, skylight systems require some design considerations especially on the choice of materials for achieving durability and sustainability. According to Crisman (2010) the physical properties of glazing materials are divided into several factors: thickness, colour, mass, physical and visual density, texture and temperature or thermal behaviour. For instance, the different thickness of glazing and various sorts of colours influence the amount of daylight and solar heat being transmitted (Garg, 2007; Kittler, 2011).

Generally, there are several questions that have become debatable among the architects such as; How much light is transmitted through the glazing?; How much of the direct beam sunlight is diffused?; How much of the sun's radiant heat is transmitted through the glazing?; How much heat from the air will pass through the glazing? (Heschong, 1998). To answer these questions, the identification of the basic physics concepts of sunlight characteristics is required.

\subsection{Glazing and Solar Radiation}

Generally, the sun radiates solar energy by electromagnetic waves known as the solar spectrum. The solar spectrum that reaches the ground is divided into three bands: Ultra-violet light, Visible light and Infra-red (James, 2001; Kittler, 2011) as shown in Figure 1(a). Solar light represents about $47 \%$ of the total solar radiation that falls in the skylight systems. Natural light is divided into sunlight and daylight, and both of them have different levels of energy and impact. The velocity of light is approximately $300,000 \mathrm{~km} / \mathrm{s}$ in space when it travels in the same medium; however when it passes from one medium to another, it will change its speed such as in glass to be $199,861 \mathrm{~km} / \mathrm{s}$. This deceleration in velocity is caused by several factors as the light is transmitted, absorbed, reflected and refracted in the glazing materials (Taylor, 2000) as shown in Figure 1(b). This means, the total amount of natural light is changeable inside a building based on the materials' properties that create different bands. 


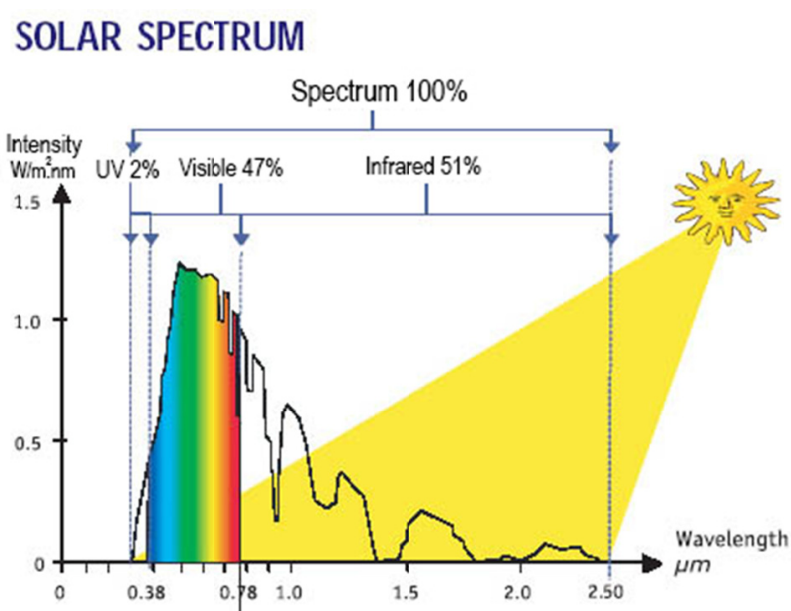

(a)

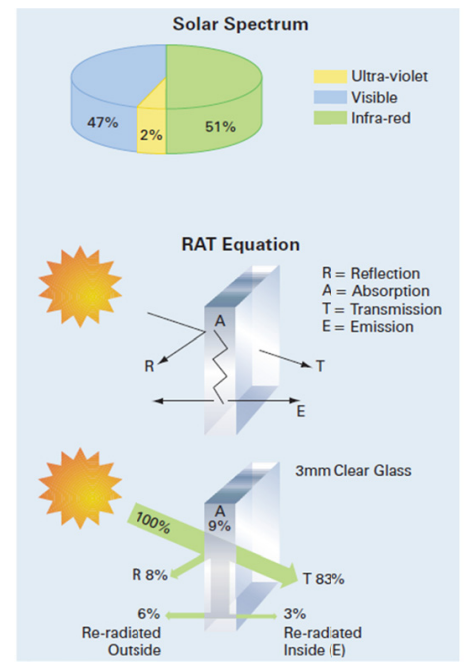

(b)

Figure 1. (a) Solar spectrum (Ais glass solutions, 2011), (b) Glazing properties (James, 2001)

From the architect's point of view, Szokolay (2008), in the book of Introduction to Architectural Science, has identified the light incident on a surface in three ways: reflected, absorbed or transmitted, of which the corresponding properties are equal to 1 . However, the refraction factor is considered to be the most important property in the design that affects reflection, dispersion and transmission, which altogether bend and change the light velocity. Refraction property relies on two factors: the incident angle $(\theta)$ and the refractive index of the material (Taylor, 2000; David \& Hunter, 2010) these two factors are very significant to be understood especially in the calculations of building design.

On the other hand, solar heat is considered as the biggest part that will be transferred by the skylight systems. It is a form of energy which is invisible to the naked eye and has a greater effect to our lives. It mainly serves as thermal energy (infrared radiation and ultraviolet) which represents around 53\% of the total solar radiation that falls onto the ground. This amount could be increased or decreased according to different variables such as the latitude and climate conditions. To understand solar heat, identifying the laws of its creation is essential. Thermodynamic laws indicate that energy cannot be destroyed but they change from one form to another. Therefore, heat occurs due to the changing energy types. Heat reaches the skylight system in two ways which are from solar radiation and from air mass. Radiation occurs when surfaces exchange electromagnetic waves but as an air mass it happens through the temperature difference between the inside and outside.

Heat transfer in the skylight system can take place based on Muneer and Kinghorn (2000), van der Linden (2002) and Szokolay (2008), where they state that firstly it is by thermal energy conveyed by solar radiation as short wave length (sunlight). Secondly, the fluctuation of solar spectrum lengths from shorter to longer waves due to environmental conditions (daylight). Thirdly, when the solar hits the skylight surface, it is absorbed then re-radiated as longer wave, near to the infrared radiation. Next, by air mass around glazing materials that transfers the heat by convection. Finally, absorbed heat conducts through the skylight material. Thus, understanding these behaviours will help to control heat transfer in the skylight design. Figure 2 shows the simplest explanation of glass behaviour.

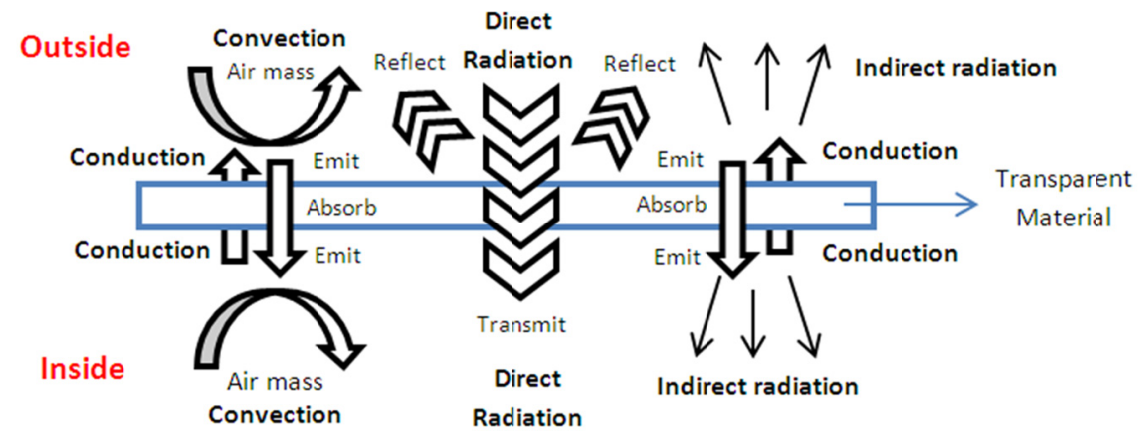

Figure 2. Thermal heat behaviour in glazing materials (general conceptualisation) 
Generally, the studies indicate that material properties behave differently at various wavelengths. For example, ordinary glass transmits a very small proportion of the sun's ultra-violet rays at $315 \mathrm{~nm}$ which is less than $1 \%$, but at $340 \mathrm{~nm}$ the transmission reaches $41 \%$ (James, 2001). This means a surface that reflects one sort of the electromagnetic spectrum may not be reflected on a various sorts of the radiation. Many surfaces, even the most shining metals which reflect light, are poor reflectors of the infrared radiation or the ultraviolet (UV) radiation. (Natural Radiation Laboratory, 2011). On the other hand, a surface that readily reflects a specific wavelength of radiation does not absorb much of that radiation, and vice versa.

\subsection{Glazing Factors}

Most architects and building designers tend to be confused about many factors that affect the selection of glazing materials. These factors represent the key role that affects directly the perception of the indoor environment. The performance of solar light and solar heat could be controlled if these physical factors become clear during the design stage. According to Oral (2004), Straube (2006), Garg (2007) and Szokolay (2008) these studies have discussed the most important factors that must be understood during the selection of glazing materials.

Generally, the quantity of solar light that passes a skylight is directly proportional to the visible light transmitted or visible reflectance. As an optical property, it shows the fraction of daylight or the percentage of visible light that is transmitted or reflected on the glazing. They are described as a ratio, and expressed as a number between 0 and 1 or by percentage (Heschong, 1998). Glazing with a high visible transmittance delivers sufficient daylight and perfect views; however, it could generate glare problems. Meanwhile, glazing with low visible transmittance provides gloomy interiors that obscure views under some weather conditions, as shown in Figure 3. However, some glazings can have high visible transmittance, and views tend to be diminished such as through patterned or frosted glass (O'Connor et al., 1997). For example, single clear glass has high percentage of VLT by about 0.9, whereas metallic coating as the reflective material has a lower VLT as 0.05 (O'Connor et al., 1997).

Refractive index, spectral selectivity and glazing colours are other factors representing the core of the light quality and efficiency calculation. The first factor refers to the percentage of light that will bend and change its character when passing from one medium into another, such as in the glass. Its importance increases when more than a single layer is used. Secondly, it identifies the ability of a glazing material to react differently to various wavelengths of solar energy. Its character identifies the amount of infrared radiation (thermal energy). Thirdly, it controls the appearance of the view and human mood in interior finishes and is a dominant determinant of the exterior appearance of the building (Heschong, 1998; Kittler, 2011).

Furthermore, the diffusion property is another important factor that determines the levels of direct sunlight and serves as a significant feature in selecting a skylight. It can maximize the spread of daylight in the building interiors and minimize glare and hot spots. The importance is to meet the requirements of energy efficiency (Heschong, 1998). Many of the glazing manufacturers use a white pigment, embedded fibers or a prismatic surface to enhance glass diffusion. Unfortunately, many of the manufacturing companies do not provide the specifications on the diffusion properties of glazing products (Collaborative for High Performance Schools, 2002).

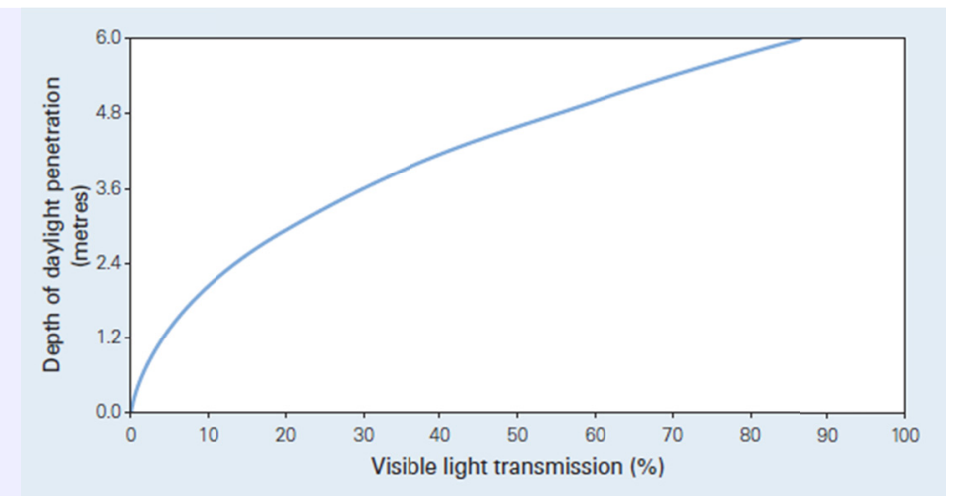

Figure 3. Depth of daylight penetration in different types of glazing materials based on the VLT (James, 2001)

On the other hand, the quantity of solar heat that passes a skylight is another issue. The amount of solar radiation that is reflected, absorbed and transmitted constitutes the factor which specifies the portion of thermal heat 
transferred. Generally, the amount of the radiant heat that passes through a skylight depends greatly on the chemical structure of the glazing material. Every material responds differently to the diverse portions of the sun's spectrum. The characteristics of these materials could reflect some wavelengths, while absorbing some and transmitting the rest. According to Lee (2006) the National Fenestration Rating Council identifies two important characteristics that should be taken into account namely the solar heat gain coefficient (SHGC) and U-value or $\mathrm{R}$-value of the overall resistance of all types of heat flow. The amount of heat that passes through transparent materials depends on the Solar Heat Gain Coefficient (SHGC) which measures the amount of the solar spectrum that will penetrate a material and becomes heat inside the building. Every material has various levels of SHGC, whereby if a large portion of radiation is transmitted then this material has a very high SHGC, and vice versa. However, if the non-visible spectrums of solar radiation are absorbed, rather than reflected or transmitted, then the glazing material itself will heat up and some of the heat will be conducted downward into the space (Collaborative for High Performance Schools, 2002).

There is a misunderstanding of the Solar Heat Gain Coefficient (SHGC) and Shading Coefficient (SC) which are often used interchangeably. Both of them determine how much of the overall solar radiation will pass the transparent materials and at last be converted into heat as shown in Figure 4. Shading coefficient (SC) is considered to be less accurate due to the assumption that all wavelengths of light are reflected or absorbed at the same rate. This provides adequate accuracy, as long as you are only evaluating the solar heat gain through a single layer. By contrast, the SHGC is preferred more because it is accurate for variations in reflectance and absorption for various wavelengths through multiple layers of transparent materials, and the fact that it can handle a wider range of materials (Heschong, 1998).

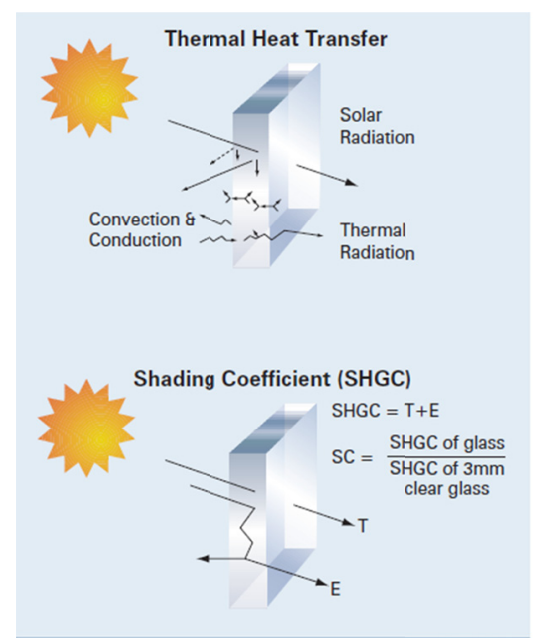

Figure 4. Thermal heat transfer (James, 2001)

Another controlling factor is the $\mathrm{U}$-value as it represents the rate of the heat flow through the glazing as a result of thermal conductance and the temperature difference between the outdoors and indoors. It is expressed as a number, where the lower the number is, the greater the protecting qualities of the glass. In fact, the U-values of the centre-of-glass (COG) are normally lower than the whole-window $\mathrm{U}$-values (which is the overall U-factor of the glazing, plus the spacer and frame system) due to the effect of the frame and mullions (O'Connor, 1997). Based on the Collaborative for High Performance Schools (2002) it indicates that a U-factor in single pane windows normally is in the range of 1.0 to $1.2 \mathrm{COG}$; while the double pane windows range from 0.65 to 0.45 COG. With low-e coatings, multiple glazing and inert gas filling the U-factor can be as lower as 0.1 COG. Furthermore, there are very common factors which must always be taken into consideration such as thickness, density, thermal conductivity and specific heat that indicate the performance and the quality of materials selected.

Finally, understanding the relationship between solar light and solar heat could be summarized by considering the relationship of visible light transmits (VT) and solar heat gain coefficient (SHGC) which portrays the concept of an efficient glazing material (Lee, 2006). The light-to-solar gain ratio (LSG) represents this relationship, favouring low SHGC in conjunction with a comparatively high visible transmittance. In fact, every material has various amounts of LSG as shown in Figure 5. For instance, the glazing with dark gray and bronze 
tints have a low SHGC and may also have a low VLT while low-e products and blue/green tints have the lowest SHGC with the highest VLT (Collaborative for High Performance Schools, 2002). Furthermore, Table 1 summarizes the most important factors that every designer should consider during the selection of glazing types.

Table 1. Glazing properties related to solar light and solar heat

\begin{tabular}{cc}
\hline Light & Heat \\
\hline Visible Light & Solar Energy Transmission \\
Transmittance & \\
Visible Light Reflectance & Solar Energy Absorption \\
Visible Light Absorption & Solar Energy Reflection \\
Diffusion & U-Value or R-Value \\
Refractive Index & Solar Heat Gain \\
& Coefficient \\
Spectral Selectivity & Shading Coefficient \\
Colour Rendering & Specific Heat \\
Dispersion & Conductivity \\
\multicolumn{2}{c}{ Thickness } \\
LSG = VT/SHGC
\end{tabular}

\begin{tabular}{|c|c|c|c|c|c|}
\hline Type & Layers & Color & Tvis & SHGC & LSG \\
\hline \multirow{6}{*}{$\begin{array}{l}\text { Acrylic/ } \\
\text { fiberglass }\end{array}$} & Single-glazed & Clear & 0.92 & 0.77 & 1.19 \\
\hline & & Med White & 0.42 & 0.33 & 1.27 \\
\hline & & Bronze & 0.27 & 0.46 & 0.59 \\
\hline & Double-glazed & Clear & 0.86 & 0.77 & 1.10 \\
\hline & & Med White & 0.39 & 0.30 & 1.28 \\
\hline & & Bronze & 0.25 & 0.37 & 0.67 \\
\hline \multirow[t]{3}{*}{ Fiberglass } & Insulated & Crystal & 0.30 & 0.30 & 1.01 \\
\hline & translucent & White & 0.20 & 0.23 & 0.85 \\
\hline & $\mathrm{U}-0.24$ & Bronze & 0.10 & 0.16 & 0.64 \\
\hline \multirow{6}{*}{$\begin{array}{l}\text { Poly- } \\
\text { carbonate }\end{array}$} & Single-glazed & Clear & 0.85 & 0.89 & 0.96 \\
\hline & & Bronze & 0.50 & 0.69 & 0.73 \\
\hline & & Med White & 0.37 & 0.50 & 0.73 \\
\hline & Double-glazed & Clear & 0.73 & 0.75 & 0.97 \\
\hline & & Bronze & 0.43 & 0.58 & 0.73 \\
\hline & & Med White & 0.32 & 0.43 & 0.74 \\
\hline \multirow[t]{12}{*}{ Glass } & Single-glazed & Clear & 0.89 & 0.82 & 1.09 \\
\hline & & Bronze & 0.55 & 0.64 & 0.87 \\
\hline & & Green & 0.74 & 0.59 & 1.25 \\
\hline & Double-glazed & Clear & 0.78 & 0.70 & 1.11 \\
\hline & & Bronze & 0.48 & 0.51 & 0.94 \\
\hline & & Green & 0.66 & 0.47 & 1.40 \\
\hline & Double-glazed & Clear & 0.72 & 0.57 & 1.25 \\
\hline & low-e & Bronze & 0.45 & 0.39 & 1.15 \\
\hline & & Green & 0.61 & 0.39 & 1.56 \\
\hline & Triple-glazed & Clear & 0.70 & 0.53 & 1.32 \\
\hline & low-e & Bronze & 0.42 & 0.37 & 1.14 \\
\hline & & Green & 0.61 & 0.38 & 1.61 \\
\hline
\end{tabular}

Figure 5. Table of most available materials in the market (Heschong, 1998)

\section{Types of Glazing Materials}

The increasing interest of skylights by many architects, building designers, owners is translated into their seeking to know about the performance and energy efficiency of various glazing materials used in skylights. There are different types of glazing materials engaged in the building design especially skylight systems. Glazing techniques vary based on the requirements of each project. Some architects or owners need a clear view through the glazed surface, while others seek to promote natural light of a specific space. Both glass and plastic products can support contemporary buildings while meeting the standards of both the environment and structure. However, the selection of either glass or plastic is based on several factors, including the climate, building location and cost. In fact, manufacturing companies refer to categories of skylights by their glazing, as a common term used to define how a skylight is constructed.

Glass material frequently comes to a designer's mind even though this type makes a more expensive decision. Glass can deliver different degrees of energy efficiency such as insulating glass units, laminated or tempered glass, moisture-free option and a spacer or a second sheet of glass to serve as a seal. Based on the opinion of the expert, Michael Nielsen, the President of W.S. Nielsen Skylight Systems in Georgia US, even glass has the longest life span; yet, most of the glass used today is either heat-treated or laminated and at the same time, must be made of safe glazing material (The American Architectural Manufacturer Association, 2010).

Plastic material is another type of skylight system. It is a subset of materials known as polymers which are found in many forms of materials such as polycarbonate, acrylic, copolyester, etc. According to Nielsen, plastics are cheaper than glass and is an alternative when lighter loading is a concern. In fact, the choice of the type of plastic or plastic versus glass relies totally on the user's preference and task requirements. Various plastic formulations deliver various performance characteristics.

Therefore, careful selection of skylight materials is an essential step in good daylight design. There are wide ranges of glazing materials nowadays, and these types could be summarized and divided into glass and plastic types. 


\subsection{Glass Materials}

\subsubsection{Clear Glass}

It is a conventional opening material manufactured as clear float glass. This glass can be provided by different ways as single sheet, double or triple glazed or alternatively as 'thick' glass. In a single layer it transmits approximately $85 \%$ of the light that falls upon it. Double or triple glazing will decrease light transmission to $60 \%$ and 70\%, respectively (Heschong, 1998) as shown in Figure 5. As the thickness of glass increases, the more the daylight as well as the quality of the colour will be diminished (The European Commission Directorate-General for Energy, 1994). However, the disadvantage relates to the allowance of a high transmission of daylight and high transmission of solar radiation (Phillips, 2004).

\subsubsection{Tinted Glass}

This type of glass is divided into two types. Firstly, there is the modified clear glass to create various radiant heat transmission characteristics famously known as the thicker, whereby the greater the control of radiant heat from sunlight, the lower the transmission of daylight. Secondly, the coated glass with microscopically thin layers of metallic oxides which are applied to the inside layer of glass reflects the heat away and out of the building. In fact, the first type of tinted glasses reduced solar heat gain but also cut down daylight transmission and distorted the colour (The European Commission Directorate-General for Energy, 1994). However the second type is designed to have high daylight transmission, because of the very thin layer of the reflective material (Phillips, 2004).

Generally, the standard range of colours is Bronze, Blue, Grey and Green. The colour intensity will increase with thickness while the visible light transmittance will reduce correspondingly. Currently, there are special extension of the family of tinted glass products called the supertints such as Azurlite, Arctic Blue and Evergreen/Solargreen. They are products often termed 'spectrally selective' and they deliver an excellent light transmittance while still maintaining effective solar control features. They also efficiently select the visible light band from the solar spectrum and filter out the UV and infra-red bands when compared to standard tints.

Based on James (2001) Evergreen provides $66 \%$ light transmittance compared to $43 \%$ for standard grey, $51 \%$ for standard bronze and $78 \%$ for standard green. However, as Azurlite demonstrates $71 \%$ light transmittance, the total solar energy transmitted is only $50 \%$. Optigray 23 is designed to offer much lower light transmittance of only $23 \%$ while at the same time, the total heat transmittance is reduced to $41 \%$. Finally, Supergrey provides the lowest visible light transmittance of $8 \%$.

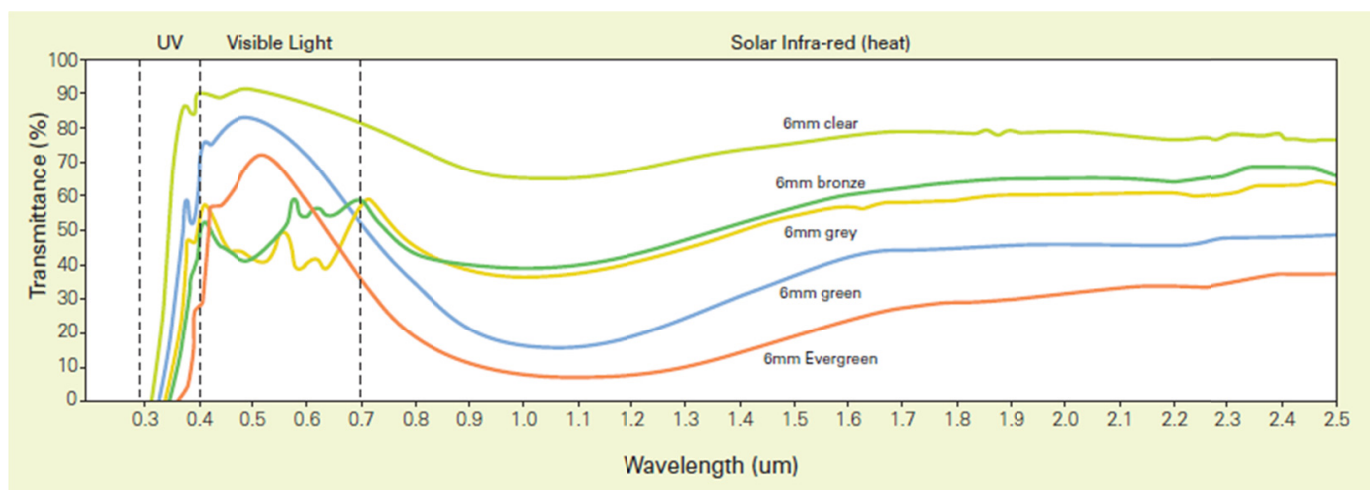

Figure 6. Transmitted energy wavelength (James, 2001)

\subsubsection{Wavelength Selective Coatings}

This group of glasses is divided into two types, firstly low-e glass (Heat glass), which has a low absorptive coating to suppress the infrared radiation exchange. It reduces heat gain by only $10 \%$ because a large percentage of the heat absorbed is re-radiated into the interior while maintaining the transmission of daylight. It is working as a selective reflector, where solar reflectance is low and consequently the solar transmission is quite high. The performance is significant, as $60 \%$ of the heat lost through ordinary windows is explained by the long-wave infrared radiation. However, low-e glass can shut down the infrared radiation especially with double glazing window thermal resistance (Glass for Europe, 2005). The second type is a reflective glass- generally this type of glass blocks solar radiation light as well as heat effectively, and the reflectance ratio reaches up to $50 \%$. 
However, this coating has a problem with heat gain and daylight, yet it may prove to be beneficial especially in winter time (Cardinal Glass Industries, 2011).

\subsubsection{Insulating Glass}

There are several types of insulating glass under this category, Transparent Insulation Materials (TIM) and Aerogel windows. Transparent Insulation Materials (TIM) have been developed primarily as insulating materials for wall structures, but over the years, this glass has become famously and broadly implemented in skylight systems as they can function as a glazing material as well. Commonly, this type of glazing consists of glass or plastic capillaries, fibre and gel or honeycomb structures sandwiched between two glass panes. Light transmission in this type ranges from $45 \%$ to $80 \%$, with a decrease of roughly $8 \%$ for each sheet of protective glass used. In fact, the TIM can be combined into purpose-made skylight assemblies; however the costs tend to be about three times the cost of conventional double-glazed windows (Muneer \& Kinghorn, 2000).

The second type is Aerogel windows. This type of glass is used in preventing heat loss from the interior. The criteria of these windows are that they are transparent, have low density, are extremely solid, have low thermal conductivity and are fragile. They fill the air space between window panels with a micro-porous silicate foam material which decreases thermal transmission. The daylight transmission is moderate, being in the range of $50 \%$ for $12 \mathrm{~mm}$ glazing (The European Commission Directorate-General for Energy, 1994). There are two types, namely granular (in the form of granules) and monolithic (in the form of continuous slabs).

\subsubsection{High Tech Glazing}

There are few types of glass under this category. The most developed technique is the photovoltaics, where the glass sandwiches the solar cells designed to produce electricity from the solar radiation. Another type of high tech glass deserves an indication but is not at present, economical. They are the photochromic glasses, which respond directly to an environmental stimulus. These types of glass are designed to respond indirectly by the application of an electrical current which changes their visual and thermal features (Phillips, 2004). This type of glass is divided into three types namely Electrochromic, Thermochromic and Photochromic. The first model changes its optical absorption properties in response to an externally applied electric field and becomes dark or cloudy. The second type switches between a heat-reflecting and a heat-transmitting state at selected temperature thresholds. Finally, the last type of glass responses to changes in light intensity and gradually darkens and lightens. The function of all these glasses types is evident in the selective blocking of radiation (The European Commission Directorate-General for Energy, 1994).

Other types that could also fall into this category is the holographic film which is a technique used to diffract solar radiation instead of blocking it. The advantage of this type is that it is able to deal directly with direct incoming sunlight. This type of glazing can be tuned to reflect and diffract solar radiation at any waveband in the solar spectrum, while allowing 75-80\% transmittance in the visible waveband (Muneer \& Kinghorn, 2000).

\subsubsection{Miscellaneous Glazing}

This category of glass includes a number of different types of glazing, largely due to the difficulty of classifying them together into a single group. They comprise of the following; laminated glass and wired glass (safety glass), vacuum windows and super windows. The laminated glass is commonly used for security reasons as resistance to impact. Generally, it is found in museums where exhibits are exposed to daylight, and therefore, it will be necessary to control the entry of the UV light. However, this type reduces the transmission of daylight. On the other hand, wired glass is also one of the types used commonly for security reasons as resistance to impact, especially for the protection of skylights. It consists of wire mesh applied in sandwiched panels within the thickness of the glass (The European Commission Directorate-General for Energy, 1994).

Furthermore, vacuum windows are a combination with a low-emissivity coating on one of the internal surfaces. This approach aims to eliminate the radiant heat transfer and cavity gas convection (Green building advisor, 2009). Finally, Super windows comprise of multiple panes of glass or plastic films, with gas cavity fillings, insulating frame and spacers and one or more low-emissivity coatings. Super windows are commercially available now and the range will continue to increase (Muneer \& Kinghorn, 2000).

Figure 7 gives a clear picture of the appearance of the glazing group that helps to generally identify the condition of the selection. 


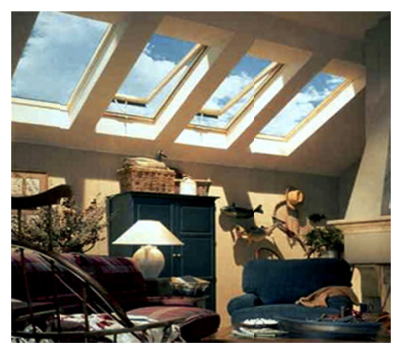

Clear float glass

Source: Larry Haight's Residential Roofing

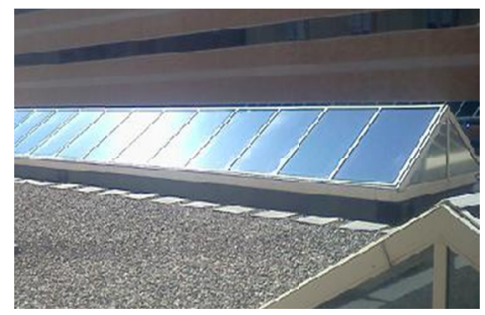

Reflective glass

Source: Solar Concepts Inc.

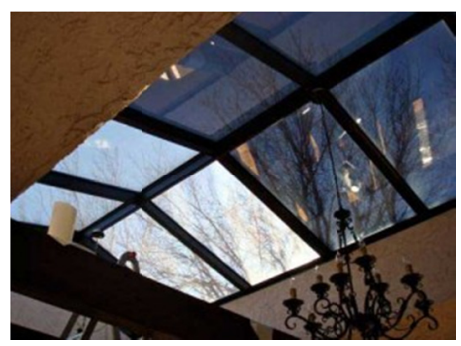

Tinted glass Source: Window Films

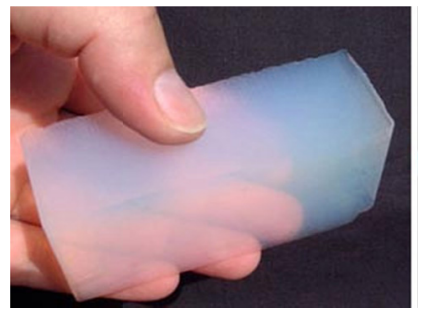

Aerogel glass Source: uSpace

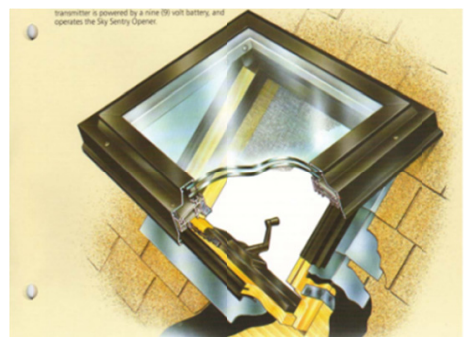

Vacuum glass

Source: Columbia Manufacturing CO

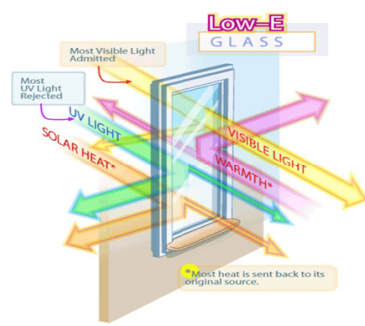

Low-E glass

Source: NCDOI OSFM Evaluation

Services

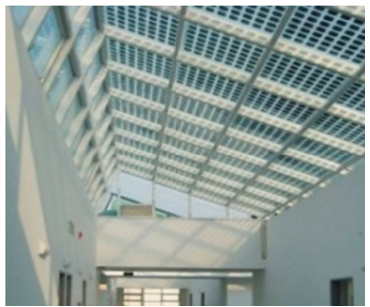

Photovoltaic glass Source: Solar Constructions
Electrochromic glass

Source: Glass on Web

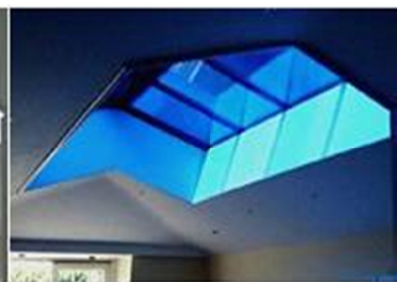

Figure 7. Different types of skylight glazing materials

\subsection{Plastic Materials}

\subsubsection{Glass Reinforcement Plastics (GRP)}

It is a very cost-effective material which is commonly used for skylight systems. The GRP provides high levels of diffused light into the building interiors and offers excellent performance properties. It is applied in all types of building functions such as industrial, sporting and commercial purposes. In most cases it is preferably due to the properties of diffused light, which minimise glare, distract shadows and incorporate UV-absorbing surface protection that eliminates long term discolouration (National Association of Rooflight Manufacturers, 2009).

\subsubsection{Poly Vinyl Chloride (PVC)}

PVC is a kind of traditional material that began to be used in the 1970s and 1980s, especially for industrial skylight applications. However, this material has poorer weathering performance and impact resistance than other alternatives. PVC requires the addition of safety measures in the skylight construction. Currently, it is rarely used in commercial or industrial applications. Even though it is not expensive, it is successful as a material for small, low-rise domestic projects (National Association of Rooflight Manufacturers, 2009).

\subsubsection{Polycarbonate}

It is a versatile material in the form of widely-used plastic from a specific group of thermoplastic polymers and which is applied extensively as a skylight glazing. It is designed to perform in a wide range of roofing and cladding applications. It is known by the trademark Makrolon and Lexan. Polycarbonate has clarity, high impact resistance, also UV coatings protection which eliminates up to $99 \%$ of UV, protecting materials and people 
beneath it. Based on the Bristol daylighting systems (2013) Polycarbonates are $100 \%$ recyclable material where most manufacturers use up to 25\% and it is one of the Leadership in Energy and Environmental Design (LEED) projects. According to Al-Obaidi et al. (2013) indicates that Polycarbonate is a very useful material for skylight systems in the tropical region. It also represents highly diffused light transmission and Low U-factors which make it a good daylighting material. It is many times stronger than glass and a great deal stronger than Acrylic which has good weathering characteristics. Polycarbonate has a great range of different colours like Acrylic that comes in clear, opal and various tints (Queensland Skylight Installation, 2013).

Based on National Association of Rooflight Manufacturers (2009), The American Architectural Manufacturer Association (2010) and Queensland Skylight Installation (2013) Polycarbonate is divided into sheet forms: Solid - Flat or Domed, Profiled and Multiwall. Solid polycarbonate provides superb workability and good optical clarity. It can be moulded into numerous shapes such as pyramids and domes. Profiled polycarbonate is a feature popular with many designers, as it matches profiled roof cladding and has very good profile accuracy. Multiwall polycarbonate is a glazing system which incorporates two layers of polycarbonate which is considered as an insulating glazing material that provides the best thermal properties. Thicker sheets with more walls achieve the highest thermal performance. Structured polycarbonate is generally applied in most domestic and commercial buildings. The visible transmittance ranges from 0.85 for clear single glazed, 0.50 for Bronze however in double glazed, 0.73 for clear and 0.43 for Bronze (Heschong, 1998).

\subsubsection{Acrylic}

Acrylic is an alternative to glass. It is a tough, transparent polymer of poly (methyl methacrylate) known as (PMMA) commonly known under the well-known trade names, Plexiglass and Lucite. Acrylic sheet is an ideal material for a wide variety of skylights systems. It has been the material of choice among manufacturers for years, all around the world due to its clarity, durability, weather resistance, impact resistance and low weight. Many colours are available but white, gray and bronze are the most common types. In fact, white is usually characterized as low, medium or high with the light transmission level of the coloured acrylic. Medium white is the most frequently used because of light and diffusion. Low white will typically produce $100 \%$ diffusion and $25 \%$ light transmission. Medium generally produces $95 \%$ to $100 \%$ diffusion and $50 \%$ light transmission. High produces $20 \%$ diffusion and $75 \%$ light transmission. However, gray and bronze colours are referred as tints and a standard medium level of tint will transmit light around $30 \%$ and produce $0 \%$ to $5 \%$ diffusion. Generally, double glazed skylights are the most common glazing used for industrial and commercial purposes (Queensland Skylight Installation, 2013).

Furthermore, Solar Heat Blocker Acrylic is one of the acrylic materials which are spectrally selective Low-E coatings that have a unique feature which allows high levels of visible light transmission while decreasing solar heat transmission. The thickness of this coating delivers various levels of light transmission, infrared and ultraviolet. Solar Heat Blocker Acrylic can transmit visible light from $70 \%$ to $20 \%$; block $50 \%$ to $95 \%$ of infra up to $99.9 \%$ of the UV light (Bristol daylighting systems, 2013).

\subsubsection{Fiberglass}

Fiberglass has been used for nearly forty years and has some superior performance qualities compared to other common skylight materials. It comes with different profiles such as monolithic, flat, dome or various other profiles and can come in two pieces with an air space for insulation.

Fiberglass has lower solar heat gain coefficient and comparable insulating (U-Factor) properties in comparison to polycarbonates, copolyesters and acrylics. In fact, it absorbs the UV B radiation efficiently, while permitting the UV A radiation. The increasing in obscuring the warm part of the light spectrum will curb the needing of air conditioning. It has a significantly different appearance than other skylight materials. Its colour is soft brown and with age, it tends to turn into various shades of yellow. In fact, in terms of the light transmission, the colour in the skylight is a matter of perception rather than reality. Of all colours, yellow negatively affects the perception of any plastic's clarity or light transmission (The American Architectural Manufacturer Association, 2010; Bristol daylighting systems, 2013). The visible transmittance ranges from 0.30 for Crystal and 0.20 for White with SHGC 0.30 and 0.23, respectively (Heschong, 1998).

\subsubsection{Copolyester}

Copolyester is similar in composition to the plastic used in water bottles, but is more impact resistant known by the trade names of UltraTuf-CX and TiGlaze ST. Copolyester has an excellent clarity, high diffusion that provides impact resistance and thermoform requiring less energy and lower temperatures compared to other plastic glazing materials. It is normally supplied for glazing applications in clear and translucent white sheet. It 
costs approximately $20 \%$ more than the acrylic for general purpose and it is roughly 7 to 8 times stronger than its typical service life of twenty years. However, this material can be damaged by the UV radiation (Bristol daylighting systems, 2013).

Figure 8 and 9 give a clear picture of the performance and the appearance of the plastic glazing group that help to identify the selection condition in general form.

\begin{tabular}{|c|c|c|c|c|c|}
\hline Material & GRP & $\begin{array}{c}\text { Polycarb'te } \\
\text { Flat }\end{array}$ & $\begin{array}{c}\text { Polycarb'te } \\
\text { Multi Wall }\end{array}$ & Safety Glass & PVC \\
\hline Transparency & Medium & Excellent & Medium & Excellent & Excellent \\
\hline Untinted Translucency & Excellent & Good & Good & Medium & Medium \\
\hline Strength & Excellent & Excellent & Excellent & Medium & Poor \\
\hline Fire Rating & Class 0,1,3,4 & Class 0,1,(Y) & Class 0,1,(Y) & Class 0,1 & Class 1,(Y) \\
\hline UV Resistance & Good & Good & Good & Excellent & Medium \\
\hline Temperature Resistance & Excellent & Good & Good & Good & Medium \\
\hline Thermal Insulation & Good & Good & Excellent & Good & Good \\
\hline Sound Insulation & Good & Good & Medium & Excellent & Good \\
\hline Rigidity & Excellent & Good & Excellent & Excellent & Good \\
\hline Patterns & No & Yes & No & Yes & No \\
\hline Colours & Yes & Yes & Yes & Yes & Yes \\
\hline Cold Curving & Good & Excellent & Good & No & Good \\
\hline Formability & No & Excellent & No & No & Excellent \\
\hline
\end{tabular}

Figure 8. Table of comparison of several plastics glazing materials (National Association of Rooflight Manufacturers, 2009)

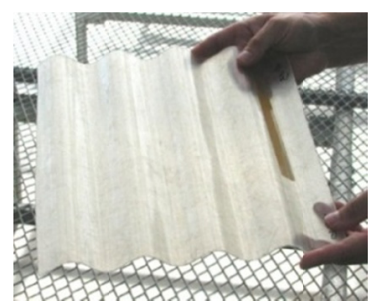

GLASS REINFORCED PLASTIC

Source: Greenhouse Glazing

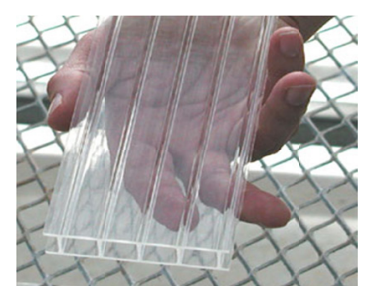

Multiwall acrylic sheet Source: Greenhouse Glazing

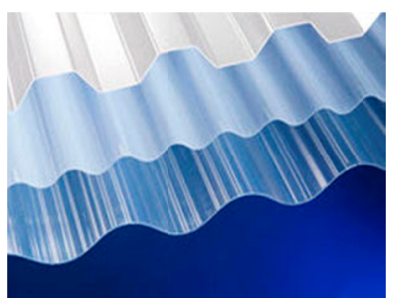

PVC Plastics

Source: Direct Industry, Corrugated Pvc Panel

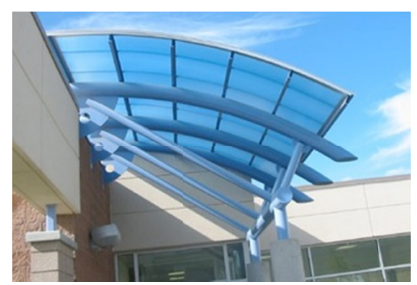

Fiberglass

Source: Building Solution

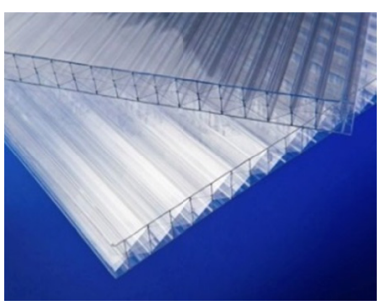

Multiwall polycarbonate sheet Source: Direct Industry, multiwall-polycarbonate

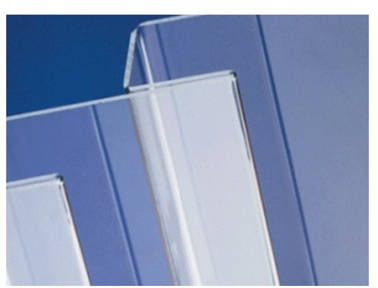

Copolyester

Source:_Lavorazione Plexiglas Torino

Figure 9. Different types of plastics glazing materials

\section{Evaluation}

Glass and plastic materials come in a variety of choices although it is a fact that every design has its special characteristics. Evaluating the basic facts is necessary for building professionals to understand the great difference, for instance:

- Single clear pane glazing could be effective in mild climates, where solar radiation is not very moderate as opposed to the cold or hot climate. On the other hand, the selection of dual or triple-pane could be more effective in cold or hot climate despite its high cost. 
- Glass material can deliver different degrees of energy efficiency; however it is an expensive decision to make. Meanwhile, plastics cost less and this is very practical when lighter loading is a concern.

- The visible transmittance to control the glare should be taken into consideration with moderate visible transmittance of (50-70\% is a good starting point) this decision rely on the visual tasks, opening size and glare sensitivity.

- The size of glazing material especially for larger opening area requires lower visible transmittance and lower solar heat gain coefficient and vice versa.

- The differences between the dark glass types as modified glass and coating glass have to be accounted for. The earlier glass types provide good solar control; however many dark glazings block light more than heat. Dark glass creates gloomier interior atmosphere that might be the cause of absenteeism, reduced productivity and increased occupant discomfort on a sunny day. However, coating glass is designed to have high daylight transmission.

- It is not possible that most of the plastic materials have sealed insulating glass (SIG) configurations and protective solar (low-e) coatings due to the inherent permeability of plastics. However, the U-factor can be decreased through the use of multiple layers of plastics. Recently, new technological advances have led to the reduction of solar heat gain by as much as 20 to $40 \%$ by using special plastic formulations and coatings.

- UV resistance is very important in glass and particularly in plastic. The review shows that Polycarbonate represents the best plastic materials however fiberglass is the worst due to its ability to absorb UV B radiation efficiently, while permitting UV A radiation. as Also, Copolyester can be damaged by the UV radiation

- The colour of glazing materials plays an important role for tinted glass, as every colour delivers different levels of light and different impacts even with the same thickness. On the other hand, as far as the changeability of material colour such as fiber glass is concerned, the review shows that the colour soft brown changes with age and it tends to turn into various shades of yellow.

- Glazing is not the only element that can endure the front of the solar beam. There are other methods that could be used to overcome this such as the orientation of skylight design, shading elements etc.

- Understanding the concept of an efficient glazing material for daylighting or the light-to-solar gain ratio (LSG) is very significant as this term refers to the low SHGC in conjunction with a comparatively high visible transmittance.

- It is desirable to evaluate the manufacturers' literature for the desired visible transmittance and the lowest possible solar heat gain coefficient.

\section{Conclusion}

The review highlights the most important concern relating to the physical issues connected with the architectural designs. It identifies the most significant factors required during the design stage. The research shows that by comprehending the harmony of physical factors and glazing types, it helps to meet the requirements of most new energy-efficient buildings. Glazing materials must first be understood environmentally before any further decision is made. As architects, building designers and owners, this review offers the opportunity to evaluate the performance and energy efficiency of various glazing materials used on skylights. Even more so, it also offers greater flexibility in product selection, improves comfort in perimeter zones, reduces mechanical loads and improves energy performance.

\section{Acknowledgements}

The authors would like to thank Universiti Sains Malaysia (USM) for the financial support provided for this research project.

\section{References}

AdelAide City CounCil. (2013). Energy Efficient glazing - Green BuildinG FACt Sheets. Retrieved November 12, 2013, from http://www.adelaidecitycouncil.com/assets/acc/Development/planning-building/docs/glazing_fact_sheet.pdf

Ais glass solutions. (2011). Solar spectrum. Retrieved November 12, 2013, from http://gal6.piclab.us/key/AIS\%20Glass\%20Solutions

Al-Obaidi, K. M., Ismail, M., \& Abdul Rahman, A. M. (2013). An innovative roofing system for tropical 
building interiors: Separating heat from useful visible light. International Journal of Energy and Environment, 4(1), 103-116.

Bristol daylighting systems. (2013). Glazing materials used in plastic unit skylights. Retrieved November 12, 2013, from http://www.bristolite.com/Interfaces/glazing_materials.aspx\#SH1

Building Solution. Fiberglass. (n.d.). Retrieved November 12, 2013, from http://www.buildingsolution.net/Images/product_images/Extech/3100seriesAA.jpg

Cardinal Glass Industries. (2011). Architectural Glass Guide. Retrieved November 12, 2013, from http://www.cardinalcorp.com/wp-content/uploads/pdf/cardinal-architectural-brochure.pdf

Carmody, J. (2007). Residential windows: A guide to new technologies and energy performance. WW Norton \& Company.

Chris A., FAIA, RIBA. (2009). Building Envelope Design Guide. National institute of building science. Retrieved October 12, 2013, from http://www.wbdg.org/design/env_introduction.php

Crisman, P. (2007). Materials. National institute of building science. Retrieved December 12, 2013, from http://www.wbdg.org/resources/materials.php?r=env_introduction

Collaborative for High Performance Schools. (2002). CHPS Best Practice Manual (DAYLIGHTING AND FENESTRATION DESIGN) (pp. 209-256). Retrieved December 12, 2013, from $\mathrm{http} / / /$ www.lightingassociates.org/i/u/2127806/f/tech_sheets/Daylighting_and_Fenestration_design.pdf

Columbia Manufacturing CO. (n.d.). Architectural and Commercial Skylight System. Retrieved November 12, 2013, from http://www.columbiaskylights.com/downloads/Literature/Columbia\%20Glazing\%20Systems.pdf

David, G., \& Hunter, M. D. (2010). Optics and Refraction Outline, Spring. Retrieved November 12, 2013, from http://www.childrenshospital.org/cfapps/research/data_admin/Site2815/Documents/Optics\%20and\%20Refr action\%20for\%20podcast.pdf

Derek, P. (2004). Daylighting: Natural Light in Architecture. Elsevier.

Direct Industry. (n.d.). Corrugated PVC Panel. Retrieved November 12, 2013, from http://img.directindustry.com/images_di/photo-g/corrugated-pvc-panel-50058-5250749.jpg

Direct Industry. (n.d.). Multi Wall Polycarbonate. Retrieved November 12, 2013, from http://img.directindustry.com/images_di/photo-g/x-wall-multiwall-polycarbonate-sheet-pc-50058-2615847.j $\mathrm{pg}$

Dong, B., Lee, S. E., \& Sapar, M. H. (2005). A holistic utility bill analysis method for baselining whole commercial building energy consumption in Singapore. Energy and buildings, 37(2), 167-174.

Edward, T. (2005). Daylighting Design in Libraries. supported by the U.S. Institute of Museum and Library Services under the provisions of the Library Services and Technology Act, administered in California by the State Librarian. Retrieved from http://www.librisdesign.org

Freire, R. Z., Mazuroski, W., Abadie, M. O., \& Mendes, N. (2011). Capacitive effect on the heat transfer through building glazing systems. Applied Energy, 88 (12), 4310-4319.

Garg, N. K. (2007). Guidelines for Use of Glass in Buildings. New Age International (P) Ltd.

Glass for euorpe. (2005). Low-E Insulating Glass for Energy Efficient Buildings. Retrieved November 12, 2013, from

http://www.pilkington.com/assetmanager_ws/fileserver.aspx?cmd=get_file\&file_id=3557\&digest=W/hLG6 OIjzdEWGcWYfEWwA==\&ct=pdf\&file_name=Low-E_Insulating_Glass.pdf

Glass on Web. (n.d.). Smart glass / Electrochromic glass. Retrieved November 12, 2013, from http://www.glassonweb.com/utils/photos/smartglass_electrochromic_glass_big.jpg

Green building advisor. (2009). Vacuum-Insulated Windows. Retrieved November 12, 2013, from http://www.greenbuildingadvisor.com/blogs/dept/energy-solutions/vacuum-insulated-windows

Greenhouse Glazing. (n.d.). Greenhouse Glazing. Retrieved November 12, 2013, from Materials.http://faculty.yc.edu/ycfaculty/ags250/week05/greenhouse_glazing_materials/Greenhouse_Glazin g_Materials_print.html

Gueymard, C. A., \& DuPont, W. C. (2009). Spectral effects on the transmittance, solar heat gain, and 
performance rating of glazing systems. Solar Energy, 83(6), 940-953.

Hassid, S. (2011). Developments in the residential energy sector in Israel. Advances in Building Energy Research 5:71-9.

Heschong, L., \& Resources, E. D. (1998). Skylighting Guidelines. Southern California Edison.

James, G. Group. (2001). G.James is a glass Handbook. Retrieved November 12, 2013, from http://gjames.com/professional/glass-resources/glass-handbook

Kim, J. T., \& Todorovic, M. S. (2013). Tuning control of buildings glazing's transmittance dependence on the solar radiation wavelength to optimize daylighting and building's energy efficiency. Energy and Buildings.

Kittler, R., Kocifaj, M., \& Darula, S. (2011). Daylight Science and Daylighting Technology: Springer.

Laouadi, A., Atif, M. R., \& Galasiu, A. (2002). Towards developing skylight design tools for thermal and energy performance of atriums in cold climates. Building and environment, 37(12), 1289-1316.

Laouadi, A., Atif, M. R., \& Galasiu, A. (2003). Methodology towards developing skylight design tools for thermal and energy performance of atriums in cold climates. Building and environment, 38(1), 117-127.

Larry Haight's Residential Roofing. (n.d.). Skylights. Retrieved November 12, 2013, from http://www.larryhaight.com/filestore/Skylites/skylight\%20jan\%202002.jpg

Lavorazione Plexiglas Torino. (n.d.). Copolyester. Retrieved November 12, 2013, from http://www.lpt.it/en/products/single?id=elemento8

Lee, E. S., Selkowitz, S. E., Clear, R. D., DiBartolomeo, D. L., Klems, J. H., Fernandes, L. L., \& Yazdanian, M. (2006). A Design Guide for Early-Market Electrochromic Windows.

Levermore, G. (2008). A review of the IPCC Assessment Report Four, Part 1: the IPCC process and greenhouse gas emission trends from buildings worldwide. Building Services Engineering Research and Technology 32, $349-61$.

Masoso, O. T., \& Grobler, L. J. (2010). The dark side of occupants behaviour on building energy use. Energy and Buildings, 42, 173-177.

Muneer, T., \& Kinghorn, D. (2000). Windows in buildings: thermal, acoustic, visual and solar performance. Architectural Press.

National Association of Rooflight Manufacturers. (2009). Natural Daylight Design Through Rooflighting, $\begin{array}{llll}\text { Amendments. } & \text { Retrieved } & \text { November } & \text { 2013, from }\end{array}$ http://www.narm.org.uk/uploads/pdfs/J2335\%20Natural\%20Daylight\%20Design.pdf

Natural Radiation Laboratory. (2011). INFRARED RADIATION. Retrieved November 12, 2013, from $\mathrm{http} / / /$ www.esr.cri.nz/competencies/ncrs/publications/Documents/is13.pdf

NCDOI OSFM Evaluation Services. (n.d.). Theory of Low E. Retrieved November 12, 2013, from http://www.ncdoi.com/OSFM/Engineering_and_Codes/Documents/whitepaper_2012/2012\%20Low\%20E\% 20Glazing_.pdf

O'Connor, J., Lee, E., Rubinstein, F., \& Selkowitz, S. (1997). Tips for daylighting with windows. Lawrence Berkeley National Laboratory.

Oral, G. K., Yener, A. K., \& Bayazit, N. T. (2004). Building envelope design with the objective to ensure thermal, visual and acoustic comfort conditions. Building and Environment, 39(3), 281-287.

Queensland Skylight Installation. (2013). Glazing Materials for Skylights. Retrieved November 12, 2013, from https://www.qldskylights.com.au/Glazing-Materials-Skylights

Solar Concepts Inc. (n.d.). Reflective glass. Retrieved November 12, 2013, from http://www.solarconcepts1.com/blog/wp-content/uploads/2013/03/sc1.jpg

Solar Constructions. (n.d.). Transparent solar panels. Retrieved November 12, 2013, from http://www.solar-constructions.com/wordpress/transparent-solar-panels/

Straube, J. (2006). The building enclosure (pp. 1-12). The building science press. Retrieved November 12, 2013, from http://www.buildingscience.com/doctypes/digests

Szokolay, S. V. (2008). Introduction to architectural science: the basis of sustainable design. Architectural Press.

Taylor, A. E. F. (2000). Illumination Fundamentals. Rensselaer Polytechnic Institute. 
The American Architectural Manufacturer Association (AAMA). (2010). Glass or Plastic: The Question for Skylights. Retrieved November 12 , 2013, from http://www.aamanet.org/news/1/10/52/products/312/glass-or-plastic-the-question-for-skylights

The European Commission Directorate-General for Energy (DGXVII). (1994). Daylighting in Buildings, For. Energy Research Group, School of Architecture, University College Dublin, Richview, Clonskeagh, Dublin 14, A THERMIE PROGRAMME ACTION.

uSpace. (n.d.). Silica Aerogels as an Insulator in the Home and Workplace. Retrieved November 12, 2013, from http://uspace.shef.ac.uk/docs/DOC-51449

van der Linden, B. J. (2002). Radiative heat transfer in glass: the Algebraic Ray Trace method. Technische Universiteit Eindhoven.

Window films. (n.d.). Solar-Films. Retrieved November 12, 2013, from http://windowfilmsni.com/Solar-Films

\section{Copyrights}

Copyright for this article is retained by the author(s), with first publication rights granted to the journal.

This is an open-access article distributed under the terms and conditions of the Creative Commons Attribution license (http://creativecommons.org/licenses/by/3.0/). 